\title{
Levels of Stress and Characteristics of Perfectionism in CSD Students
}

Ann R. Beck

Illinois State University, arbeck@ilstu.edu

Heidi R. Verticchio

Illinois State University, hrfritz@ilstu.edu

Ali Miller

Illinois State University, armill3@ilstu.edu

DOI: https://doi.org/10.30707/TLCSD4.1/JNUS7982

Follow this and additional works at: https://ir.library.illinoisstate.edu/tlcsd

Part of the Communication Sciences and Disorders Commons

\section{Recommended Citation}

Beck, Ann R.; Verticchio, Heidi R.; and Miller, Ali (2020) "Levels of Stress and Characteristics of Perfectionism in CSD Students," Teaching and Learning in Communication Sciences \& Disorders: Vol. 4: Iss. 1, Article 3.

DOI: https://doi.org/10.30707/TLCSD4.1/JNUS7982

Available at: https://ir.library.illinoisstate.edu/tlcsd/vol4/iss $1 / 3$

This Scholarship of Teaching and Learning Research is brought to you for free and open access by ISU ReD: Research and eData. It has been accepted for inclusion in Teaching and Learning in Communication Sciences \& Disorders by an authorized editor of ISU ReD: Research and eData. For more information, please contact ISUReD@ilstu.edu. 


\title{
Levels of Stress and Characteristics of Perfectionism in CSD Students
}

\begin{abstract}
An electronic survey was sent to the Midwest Clinic Directors' Listserv requesting they distribute it to students in their CSD programs. The survey collected information about demographics, and students' top three stressors and stress management practices. Students were also asked to complete the 10-item Perceived Stress Scale (PSS; Cohen, 1994) and the Almost Perfect Scale-Revised (APS-R; Slaney, Rice, Mobley, Trippi, \& Ashby, 2001). A total of 278 CSD undergraduate and graduate students from 15 Midwest institutions responded to the survey. No differences were found between undergraduate and graduate responses to the PSS and the APS-R. Twenty-six percent of the respondents were classified as nonperfectionists, $33 \%$ as adaptive perfectionists, and $41 \%$ as maladaptive perfectionists. A relationship was found between perceived stress and perfectionism such that respondents with higher levels of perceived stress tended to be classified as maladaptive perfectionists and those with lower levels of perceived stress tended to be classified as adaptive perfectionists. Similarities and differences were found between undergraduates and graduate students in terms of stressors; close to $45 \%$ engaged in a stress management practice. Importance of such practices is discussed.

\section{Keywords}

CSD students, stress, perfectionism

\section{Cover Page Footnote}

Financial disclosure statements: Ann Beck is employed by Illinois State University, at which the survey was conducted. This is a continuing relationship until June 30, 2019 at which time Ann Beck will retire. Heidi Verticchio is employed by Illinois State University, at which the survey was conducted. This is a continuing relationship and Heidi Verticchio has been by ISU 20 years Ali Miller was a graduate assistant at Illinois State University during the time the survey was conducted. Ali Miller graduated and is no longer an employee of Illinois State University. Nonfinancial disclosure statements: Ann Beck has no nonfinancial disclosures. Heidi Verticchio has no nonfinancial disclosures. Ali Miller has no nonfinancial disclosures.
\end{abstract}

This scholarship of teaching and learning research is available in Teaching and Learning in Communication Sciences \& Disorders: https://ir.library.illinoisstate.edu/tlcsd/vol4/iss1/3 
Today's college students appear to be experiencing ever increasing levels of stress and anxiety (Lieberman, Raisor-Becker, Sotto, \& Redle, 2018). Many college students, especially highachieving students, are also perfectionistic (Rice \& Dellwo, 2002). Perfectionism is multidimensional and can result in either a healthy or an unhealthy personality trait (Hill \& Curran, 2016). Additionally, stress and perfectionism are related such that individuals who are perfectionistic tend to be more susceptible to stress than are those who are not perfectionistic (Hewitt \& Flett, 2002).

Many CSD students handle stress appropriately and have positive personality traits that will help them succeed in the major and eventually become high-quality professional speech-language pathologists and audiologists. Others, however, might lack stress resilience and possess some characteristics that could hinder their success in school and life. When those of us involved in CSD training programs are more informed of the possible stressors and traits that might facilitate or undermine our students' success, we can better support their academic and professional development. This paper provides information regarding CSD students' levels of perceived stress and perfectionism, items they consider primary stressors, their strategies for managing stress, and how effective those strategies are in reducing stress and unhealthy aspects of perfectionism.

\section{Stress}

Sapolsky (2004) defined stress as the state in which the body is knocked out of homeostasis (i.e., the body's ideal internal state). This alteration in homeostasis is caused by a stressor. When a stressor is a short-term physical crisis that has a clear beginning and end, the body's response to stress quickly returns it to homeostatic balance. This is the way most animals respond to stress. Sapolsky explained, however, that for humans, a stressor can be psychological as well as physical and can occur in anticipation of an event. As humans, we can quite literally "worry ourselves sick" (Sapolsky, 2004, p. 6). In the current paper, stress was defined as this internal reaction to a stressor that alters homeostatic balance.

Stress is a reality of most people's lives, including the lives of college students. Indeed, college might be a particularly stressful time of life due to its transitional nature, academic and financial demands, and new social situations (Lieberman et al., 2018). Hurst, Baranik, and Daniel (2013) suggested that some of these stressors (e.g., financial concerns) might be increasing in intensity for today's students. Lieberman et al. (2018) indicated that "many academic institutions are noting an increase in the number of student referrals for mental health counseling associated with the stress/anxiety students experience during their training" (p. 2).

These factors are of concern to educators today because high levels of stress can negatively influence skills important to academic success (e.g., ability to learn, coping skills, productivity, and overall attitude;)(Lieberman et al., 2018; Lincoln, Adamson, \& Covic, 2004; Ross, 2011; Sleight, 1985) and can result in decreases in physical and mental health (McCall, 2007). According to Bland, Melton, Welle, and Bigham (2012), high levels of stress can lead to negative outcomes for college students such as smoking, eating disorders, alcohol abuse, and an increase in the likelihood of depression. 
The stress levels of students who major in Communication Sciences and Disorders (CSD) have been the topic of several recent investigations (Beck, Seeman, Verticchio, \& Rice, 2015; Beck \& Verticchio, 2014; Beck, Verticchio, \& Schaab, 2015; Beck, Verticchio, Seeman, Milliken, \& Schaab, 2017; Lieberman et al., 2018). A consistent finding has been that CSD students demonstrate elevated levels of stress. Lieberman et al. (2018) suggested that graduate students (GS) might experience greater levels of stress than undergraduate students (UGS) because of factors such as increased financial concerns and reduced "academic support and guidance" (p. 1). Additionally, GS in clinically oriented programs, such as CSD, not only have to deal with the stresses of challenging coursework, they also have to deal with the stresses placed on them by their clinical experiences (Lieberman et al., 2018; Rizzolo, Zipp, Stiskal, \& Simpkins, 2009; Sleight, 1985).

Other researchers, however, have not found differences in the perceived stress levels of CSD UGS and GS (Beck, Verticchio, et al., 2015; Beck et al., 2017). In general, UGS at four-year colleges appear to be experiencing decreases in their perceived mental health (Lieberman et al., 2018). Such decreases could well be related to the increases in today's college students' stress. An additional stressor for CSD students could be the competitive nature of admission into CSD graduate programs. To increase their chances of being accepted, CSD UGS must strive to maintain high GPAs and engage in activities that will allow them to demonstrate their unique personal characteristics such as leadership, communication, and interpersonal skills.

Lieberman et al. (2018) concluded that, because of its potential detrimental consequences, stress experienced by students in CSD programs should be systematically investigated. These authors explored stressors and effective academic supports experienced by CSD GS. The main stressors encountered by CSD UGS and GS, however, might differ and the intensity of the stress caused by these stressors might differ as well. Therefore, further investigations should be conducted regarding how the perceived stress levels of CSD UGS and GS compare to each other and what the main stressors are for each group.

\section{Perfectionism}

One personality trait that influences how individuals experience stress is perfectionism. According to Alden, Ryder, and Mellings (2002), perfectionism is most commonly defined as "the tendency to establish excessively high personal standards of performance" (p. 375). This is the definition of perfectionism used in the current paper. Hewitt and Flett (2002) stated that individuals who are perfectionists are more likely to experience higher levels of stress than are those who are nonperfectionists. Rice, Leever, Christopher, and Porter (2006) also found a relationship between stress and perfectionism such that perfectionism strongly predicts "concurrent and prospective stress" (p. 532).

Perfectionism is a multidimensional disposition with both healthy and unhealthy dimensions (Hill \& Curran, 2016; Prud'homme, Dunkley, Bernier, Berg, Ghelerter, \& Starrs, 2017; Stoeber \& Otto, 2006; Suh, Gnilka, \& Rice, 2017). All perfectionists share the trait of striving to meet the high standards they set for themselves (Noble, Ashby, \& Gnilka, 2014). Noble et al. (2014) stated that 
individuals with healthy or adaptive perfectionism are able to be flexible with their evaluations of their performance. These individuals are often pleased with their accomplishments and are not overly distressed when they do not achieve the high standards they set for themselves. If they do fail to meet their goals, they can learn from their performance and see positive aspects of it (Christman, 2012). These students use active, task-oriented coping strategies and fewer avoidant coping strategies than do nonperfectionists or maladaptive perfectionists which makes them less likely than the others to procrastinate (Noble et al., 2014). Furthermore, students classified as adaptive perfectionists have been found to have significantly lower levels of perceived stress (Ashby \& Gnilka, 2017), greater life satisfaction, less depression, and more positive self-esteem and self-efficacy (Noble et al., 2014) than students who are not perfectionists or who have unhealthy or maladaptive characteristics of perfectionism.

Individuals who have unhealthy or maladaptive perfectionism frequently perceive themselves as unable to meet their goals and are distressed by this discrepancy (Noble et al., 2014). Maladaptive perfectionism has been associated with negative outcomes such as depression, anxiety, and suicidal ideation. Ashby and Gnilka (2017) documented that students with maladaptive aspects of perfectionism had significantly higher levels of perceived stress than did students with characteristics of adaptive perfectionism or nonperfectionism. Enns and Cox (2002) described these students as ones who hold unreasonably high and inflexible standards for themselves, who focus on not making mistakes, and who are "unable to experience pleasure from labors" (p. 51). Additionally, students who tend toward maladaptive perfectionism might display behaviors that could hinder their academic success such as being more disagreeable and aggressive than other students and experiencing a persistent sense of worry and fear of failure (Christman, 2012). These students also use more avoidant coping strategies than do other students (Noble et al., 2014) and experience difficulty writing and studying, procrastinate, and overcommit (Christman, 2012). Furthermore, Rice et al. (2006) documented that perfectionism, especially maladaptive perfectionism, was stable over time and suggested that it is important to provide support to students with maladaptive perfectionism as early as possible in their college careers.

Nonperfectionistic students are those students who do not set high standards for themselves. Some research indicated that GPAs of nonperfectionistic students do not differ from other students and that they are similar to adaptive perfectionists on factors such as social and academic integration (Rice \& Dellwo, 2002). As a group, however, they have been found to have moderate levels of depression as compared to perfectionistic students (Noble et al., 2014; Rice \& Ashby, 2007). Noble et al. (2014) found that nonperfectionistic students engaged significantly less often in active task-focused coping strategies than did perfectionistic students. These authors suggested that not only do nonperfectionists have lower expectations for themselves than do other students, they tend to be "less motivated to set goals and to make active changes to meet their goals" (Noble et al., 2014, p. 89).

Beck, Verticchio, et al. (2015) measured perfectionism in CSD UGS and GS. These authors found many of the UGS and GS were perfectionistic and a notable number of the perfectionistic students had indicators of maladaptive perfectionism. Beck et al., (2017) noted that only students from one CSD program were surveyed in the Beck, Verticchio, et al. (2015) study and so it is important to replicate these findings to determine if they hold true for students across CSD programs. Such 
information is important because it could help educators design remediations, if needed, based on students' individual and group characteristics. As Christman (2012) indicated, the ability of educators to recognize and understand the differences between aspects of perfectionism is necessary in order to assist students most effectively.

\section{Purpose statement}

Stress and perfectionism are related (Ashby \& Gnilka, 2017). As Ashby and Gnilka stated, students who have maladaptive perfectionism are more susceptible to the negative effects of stress than are students who have adaptive perfectionism. High levels of perceived stress and maladaptive perfectionism both can negatively impact students' academic success and overall well-being (Beck et al., 2017; Christman, 2012). Preliminary data indicated that the population of CSD UGS and GS contain a notable number of students who have maladaptive aspects of perfectionism (Beck, Verticchio, et al., 2015). Research has also indicated that many CSD students have moderate to high levels of stress (Beck, Verticchio, et al., 2015; Lieberman et al., 2018). To our knowledge, only two studies (Beck et al., 2017; Beck, Verticchio, et al., 2015) have investigated the characteristics of perfectionism in CSD students. Additionally, these are the only studies that have compared the perceived stress levels and characteristics of perfectionism of UGS to GS.

In order to facilitate CSD educators' efforts to tailor methods of decreasing stress and maladaptive perfectionism to specific groups of students and to enhance students' educational experiences, further systematic investigations of stress and perfectionism in CSD students should be conducted. The purpose of this study was to increase knowledge of perfectionism and stress in CSD UGS and GS in order to better support them as they move through CSD UGS and GS programs. This study addressed the following seven research questions:

1. What are the types of perfectionism found in CSD UGS and GS and how do UGS and GS compare to each other on these traits?

2. What are the perceived stress levels of CSD UGS and GS and how do the stress levels of UGS and GS compare?

3. Do perceived stress levels vary depending upon whether students are classified as maladaptive perfectionists, adaptive perfectionists, or nonperfectionists?

4. Is there a relationship between measures of negative aspects of perfectionism and perceived stress?

5. What do CSD UGS and GS cite as their top stressors?

6. What stress management practices do CSD UGS and GS engage in on their own?

7. Is there an influence of engaging in stress management practices on reducing perceived stress levels and negative aspects of perfectionism?

\section{Methods}

Procedure. The research design used was survey research. Recruitment of respondents was initiated after Institutional Review Board approval was obtained. Survey recruitment occurred in the first half of the fall semester of 2017. Respondents were recruited by sending an email to the 
Midwest Clinic Directors' Listserv. Members of the Listserv were asked to send a recruitment email containing a link to the electronic version of the survey to UGS and GS in their programs. A reminder email was sent 2 weeks following the first request. The body of the email to students contained a consent form and a link to the survey. The consent form instructed students that by clicking on the link, they were verifying they were 18 years of age or older and were giving their informed consent to participate in the study.

Participants. A total of 278 students from 15 institutions across the Midwest responded to the demographic portion of the survey. More specifically, 8 respondents came from two Michigan institutions, 41 from three Illinois institutions, 70 from three Missouri institutions, 11 from one Kansas institution, 22 from two North Dakota institutions, 51 from two Iowa institutions, 19 from one Nebraska institution, and 50 from one Wisconsin institution. Six respondents did not indicate what institution they attended. Ninety-seven of these students were UGS, 181 were GS. Of the undergraduate respondents, $11 \%(\mathrm{n}=11)$ were freshmen, $20 \%(\mathrm{n}=19)$ were sophomores, $21 \%$ $(\mathrm{n}=20)$ were juniors, and $48 \%(\mathrm{n}=47)$ were seniors. The mean age of the UGS was 20.58 with a range of 18-44. Of the $181 \mathrm{GS}, 50 \%(\mathrm{n}=91)$ were in their first year of graduate school and $50 \%$ $(n=90)$ were in their second year of graduate school. The mean age of the GS was 23.32, with a range of $21-45$. Most of the UGS and GS were white females. Please see Table 1.

Table 1

Respondent demographics

\begin{tabular}{|c|c|c|}
\hline Level & Gender & Ethnicity \\
\hline \multicolumn{3}{|l|}{ UGS } \\
\hline Freshmen & $100 \%$ female $(11 / 11)$ & $100 \%$ White $(11 / 11)$ \\
\hline Sophomores & $100 \%$ female $(19 / 19)$ & $100 \%$ White $(19 / 19)$ \\
\hline Juniors & $100 \%$ female $(20 / 20)$ & $\begin{array}{c}\text { 95\% White }(19 / 20) \\
5 \% \text { Latina }(1 / 20)\end{array}$ \\
\hline Seniors & $100 \%$ female $(47 / 47)$ & $100 \%$ White (47/47) \\
\hline \multicolumn{3}{|l|}{ GS } \\
\hline First year & $100 \%$ female $(91 / 91)$ & $\begin{array}{l}90 \% \text { White }(82 / 91) \\
5 \% \text { Latina }(5 / 91) \\
2 \% \text { Other }(2 / 91) \\
1 \% \text { Asian }(1 / 91) \\
1 \% \text { African American }(1 / 91)\end{array}$ \\
\hline Second year & $\begin{array}{c}98 \% \text { female }(88 / 90) \\
2 \% \text { male }(2 / 90)\end{array}$ & $\begin{array}{l}91 \% \text { White }(82 / 90) \\
3 \% \text { Latina }(3 / 90) \\
2 \% \text { Asian }(2 / 90) \\
2 \% \text { Other }(2 / 90) \\
1 \% \text { African American }(1 / 90)\end{array}$ \\
\hline
\end{tabular}


An exact response rate could not be calculated for several reasons. First, the Midwest Clinic Directors Listserv includes 85 members from approximately 50 institutions. The exact number of institutions represented, however, could not be determined because some members did not use their work emails to register with the Listserv. Additionally, some institutions are represented on the Listserv by more than one person. For example, there are four members of the Midwest Clinic Director's Listserv from the authors' home institution. Furthermore, the number of Listserv members who actually sent the email to their students is unknown. Given the number of schools respondents listed as their home institution and the overall number of respondents, however, the sample of CSD students who participated in the current study was heterogeneous.

Instrumentation. An electronic survey was created using Qualtrics. The initial questions on the survey collected the following demographic information: school attended, program level (i.e., graduate or undergraduate students), year within program level, gender, age, and ethnicity. Following this, respondents were asked to list their top three stressors in descending order. They were then asked if they had a stress management practice and, if they did, to indicate what it was.

To obtain measures of perfection and perceived stress, Beck, Verticchio, et al. (2015) asked their respondents to complete the Almost Perfect Scale - Revised (APS-R; Slaney, Rice, Mobley, Trippi, \& Ashby, et al., 2001; see http://kennethwang.com/apsr/scales/APS-R_96.pdf for full scale) and the 10-item Perceived Stress Scale (PSS; Cohen, 1994; see http://www.mindgarden.com/documents/PerceivedStressScale.pdf for full scale). Respondents to the current study were also asked to complete these two scales. The instructions for each scale and the exact scale items as given by the authors of the scales comprised the last items of the survey used in the current study. The entire survey used in the current study was comprised of the demographic questions listed above, items asking the respondents to list their top three stressors, to indicate if they had a stress management practice and to describe it if they did, and the APS-R and PSS scale items.

The APS-R (Slaney et al., 2001) was designed specifically for the purpose of measuring perfectionism in college students. This scale was used in the current study because the measurement of level of perfectionism (i.e., the setting of excessively high personal standards) and the type of perfectionism (i.e., adaptive, maladaptive, or nonperfectionism) in CSD UGS and GS was of interest. Enns and Cox (2002) stated that the original APS was "developed from a counseling perspective" (p. 49) with the intent of being able to differentiate adaptive perfectionists from maladaptive perfectionists. The APS was revised to measure the concept of discrepancy and to increase the clarity and strength of the Standards subscale (Slaney, Rice, \& Ashby, 2002). The resulting APS-R is a 23-item, self-report scale that has three subscales: Standards, Discrepancy, and Order.

The Standards subscale of the APS-R reflects a person's expectations regarding their performance, the Discrepancy subscale reflects the gap between a person's performance expectations and the evaluations of his or her performance, and the Order subscale reflects how important neatness and structure are to a person. Suh et al. (2017) indicated that the Standards subscale operationalizes perfectionistic strivings (i.e., setting of high standards for oneself) and the Discrepancy subscale operationalizes perfectionistic concerns (i.e., fears of making mistakes and feelings of inadequacy 
because of the discrepancy between standards set and ability to meet them). Therefore, scores on the Standards subscale are indicators of respondents' perfectionistic strivings and scores on the Discrepancy subscale are indicators of respondents' potentially unhealthy aspects of perfectionism. According to Rice et al. (2006), the score on the Order subscale does not add information to the nature of perfectionism a person might exhibit. Order subscale scores, therefore, were not analyzed in the current study.

Scores on the Standards and Discrepancy subscales can also be compared to determine type of perfectionism. Rice and Ashby (2007) reported that scores of less than 42 on the Standards subscale indicate nonperfectionism. Scores of 42 or greater on the Standards subscale indicate perfectionism. If a person's Standards subscale score is 42 or greater and his or her Discrepancy subscale score is 42 or greater, this is an indication of maladaptive perfectionism. If the Standards subscale score is 42 or greater and the Discrepancy subscale score is less than 42, this is an indication of adaptive perfectionism.

According to Suh et al. (2017), good internal consistency has been documented for college students on the Standards and Discrepancy subscales. Additionally, acceptable convergent and discriminant validity have also been found. Rice et al. (2006) reported that extensive psychometric analyses have been conducted on the APS-R to support the three subscales.

The measurement of respondents' current levels of stress (i.e., when a body is knocked out of homeostatic balance due to a stressor) was also of interest in the current study. Given that respondents were not available for biological measures of stress, the PSS was used. The PSS is a scale that has been documented have good external validity; higher scores on the PSS are related to the presence of chronic stress-related health consequences (i.e., conditions that arise when the body has been out of homeostatic balance long term)(Cohen, 1994). According to Cohen (1994), the PSS is widely used to measure perceived stress. This scale was designed to assess individuals' perceptions of the unpredictability and overwhelming nature of their current situations as well as whether or not they feel in control of life. Cohen and Janicki-Deverts (2012) confirmed that the PSS is a valid and reliable scale.

Data Analysis. Because the current study was descriptive research (i.e., survey research), statements about cause and effect could not be made. Rather, the results of the data analysis were used to discuss the differences between groups and the relationships between variables studied (Orlikoff, Schiavetti, \& Metz, 2015). Data from the APS-R's Discrepancy and Standards subscales and the PSS were quantitatively analyzed. Data from the items asking respondents to list stressors and stress management practices were qualitatively analyzed.

\section{Results}

Quantitative Data. Quantitative analyses were used to determine answers to the first, second, third, fourth, and seventh research questions. All responses were exported into SPSS version 24. The Discrepancy and Standards subscales of the APS-R were scored following directions given on the APS-R website (Slaney, 2015). Scores for respondents who answered all items on a subscale 
were computed. Higher scores on the Standards subscale indicate higher levels of perfectionistic strivings and higher scores on the Discrepancy subscale indicate higher levels of perfectionistic concerns. The PSS was scored following Cohen's (1994) directions. Scores for respondents who answered all items were totaled; higher perceived stress is reflected by higher total scores. Specific methods of data analysis are discussed in the results sections that follow.

Descriptive statistics were calculated to determine if parametric statistics could be used to analyze the scores from the APS-R Standards and Discrepancy subscales and the PSS. Results of skewness and kurtosis for scores from these three measures all fell within plus or minus one standard deviation from the mean which is "considered excellent for most psychometric purposes" (George \& Mallery, 2006, p. 99). Additionally, sample size was sufficient was to run parametric statistics.

Qualitative Data. The fifth and sixth research questions were answered using qualitative analysis as described by Hatch (2002). The initial phase involved reading the data in order to identify the level of specificity to be used in analysis. The next steps were to determine semantic relationships that existed in the data and which of these were salient relationships. These relationships were then assigned codes and the data were reread to refine salient codes.

Case summaries were run in SPSS for UGS and GS responses to the items asking them to list their top three stressors in descending order and their stress management strategies. The first author read through all responses and determined that the level of specificity that should be used was words and phrases. She also determined potential themes that arose from the data. The second author independently reviewed the data and then met with the first author to discuss and come to agreement on the level of specificity chosen for analysis and the potential themes. The third author, a research assistant, was trained on the agreed upon themes. The first and third authors independently read all responses, coded them based on the agreed upon themes, and met to determine agreement and disagreements. All instances of disagreement were discussed until concurrence was achieved.

Similarities and differences between stressors that were listed by UGS and GS were of interest. After themes regarding stressors were agreed upon, the number of times each theme was cited as a first, second, or third stressor by each group was determined and results were descriptively compared. Additionally, similarities and differences in stress management practices listed by UGS and GS were of interest. Again, the number of times each stress management theme was cited by respondents in these groups was tallied and compared descriptively.

Type of Perfectionism. To answer the first research question (i.e., What are the types of perfectionism found in CSD UGS and GS and how do UGS and GS compare to each other on these traits?), three independent t-tests were calculated to determine if differences existed between UGS and GS on measures of perfectionism and perceived stress. Because multiple t-tests were calculated, the Bonferroni correction was used to set an appropriate alpha level at .017.

The first independent t-test calculated compared the APS-R Standards subscale scores of UGS and GS to each other. Scores on the Standards subscale were the criterion variable (analogous to a 
dependent variable in experiment research) and level (UGS vs. GS) served as the classification variable (analogous to an independent variable in experimental research; Orlikoff et al., 2015). Independent t-test results indicated no difference existed between the APS-R Standards subscale scores of UGS and GS [t(235)=.65, $\mathrm{p}=.51]$. Mean score for UGS was $44.26(\mathrm{SD}=4.38)$ and for GS was 43.87 ( $\mathrm{SD}=4.42)$. Both groups of students had mean Standards subscale scores higher than the score of 42 set by Rice and Ashby (2007) as the cut-off for perfectionism.

To determine if a difference in potentially unhealthy aspects of perfectionism, as represented by APS-R Discrepancy subscale scores, existed between UGS and GS, an independent t-test with scores on the Discrepancy subscale as the criterion variable and level (UGS vs. GS) as the classification variable was calculated. Independent t-test results indicated no difference existed between the APS-R Discrepancy subscale scores of UGS and GS [t(234)=1.17, $\mathrm{p}=.24]$. Mean score for UGS was 49.82 ( $\mathrm{SD}=16.83$ ) and for GS was $46.96(\mathrm{SD}=18.13)$. Both groups of students had mean Discrepancy subscale scores higher than the score of 42 set by Rice and Ashby (2007) as the cut-off for maladaptive perfectionism.

Because no differences in Standards and Discrepancy subscale scores between UGS and GS, their responses were combined to determine the type of perfectionism demonstrated by these respondents. The directions given by Rice and Ashby (2007; see discussion in section on Surveys) were followed to analyze each respondent's scores on the APS-R Standards and Discrepancy subscales and to categorize each respondent as a nonperfectionist, an adaptive perfectionist, or a maladaptive perfectionist. Of the 234 respondents who answered all items on both the Discrepancy and the Standards subscales, 26\% $(n=62)$ were not perfectionists, 33\% $(n=77)$ were adaptive perfectionists, and $41 \%(n=95)$ were maladaptive perfectionists.

Perceived Stress of UGS and GS. To answer the second research question (i.e., What are the perceived stress levels of CSD UGS and GS and how do the stress levels of UGS and GS compare?), mean PSS scores of UGS and GS were calculated to determine the overall stress levels for these respondent groups. An independent t-test with PSS as the criterion variable and level (UGS vs. GS) as the classification variable was calculated to determine how the stress levels of UGS and GS compared to each other. Independent t-test results indicated no difference existed between the PSS scores of UGS and GS $[\mathrm{t}(254)=1.56, \mathrm{p}=.12]$. Mean score for UGS was 22.05 $(\mathrm{SD}=6.11)$ and for $\mathrm{GS}$ was $20.65(\mathrm{SD}=7.05)$. The mean PSS score for all respondents was 21.06 $(\mathrm{SD}=6.84)$.

Stress Levels by Type of Perfectionism. To answer the third research question (i.e., Do perceived stress levels vary depending upon whether students are classified as maladaptive perfectionists, adaptive perfectionists, or nonperfectionists?), a one-way analysis of variance (ANOVA) with type of perfectionism as the classification variable and PSS as the criterion variable was calculated. Alpha level was set at .05. Results of the one-way ANOVA indicated there was a statistically significant result $[\mathrm{F}(2,231)=35.51, \mathrm{p}=.000]$. Eta squared, a measure of effect size, equaled 0.24. This indicated that $24 \%$ of the variance in the criterion variable was accounted for by knowledge of the classification variable. According to Barry et al. (2016), this is a large effect size. Scheffe post hoc analyses indicated that all groups were statistically different from each other. Mean PSS 
score for adaptive perfectionists was 17.04 ( $\mathrm{SD}=5.59)$, for nonperfectionists was $20.40(\mathrm{SD}=6.66)$, and for maladaptive perfectionists was $24.73(\mathrm{SD}=5.85)$.

Relationship Between Negative Aspects of Perfectionism and Stress. To answer the fourth research question (i.e., Is there a relationship between measures of negative aspects of perfectionism and perceived stress?), a Pearson correlation coefficient between scores on the PSS and scores on the Discrepancy subscale was calculated. A statistically significant correlation was found between the PSS and Discrepancy scores $(\mathrm{Rxy}=.63, \mathrm{p}=.000)$. Those students who had high Discrepancy subscale scores tended to have high PSS scores and those who had low Discrepancy subscale scores tended to have low PSS scores.

Top Stressors Cited by UGS and GS. To answer the fifth research question (i.e., What do CSD UGS and GS cite as their top stressors?), an agreement index (number of agreements divided by the number of agreements plus the number of disagreements multiplied by 100) was calculated between coders for UGS' and GS' listings of their top three stressors. For UGS, the agreement index was $96 \%$ and for GS, it was 95\%; both of these are acceptable levels of agreement. All disagreements were discussed until coders came to consensus.

Respondents were asked to list their top three stressors in descending order. Twenty-two themes arose from the data regarding stressors; eight of these emerged as salient themes. For UGS, the most salient themes for the number one stressor were school-related stressors (course work, homework, projects, tests, grades, being prepared) and the graduate school application process. Their second rated stressors were school, social issues (friends, relationships, roommates, classmates), and finances. The most salient stressors listed as third rated stressors by UGS were school, work, and family (relationships, missing family), social issues, and finances. For GS the most salient themes in their responses for their top-rated stressor were school, clinic, and managing time (multiple demands and balancing them, schedules, deadlines, staying organized). Their second rated stressors were school, family, clinic, finances, and managing time. The salient stressors listed as third rated stressors by GS were school, managing time, social issues, and clinic. See Table 2.

Because it is logical to assume that the graduate application process would be a stressor for students who were currently applying for graduate school, the percentage of seniors, juniors, sophomores, and freshmen who listed this as either a first, second, or third-level stressor was determined. Fortyseven percent of seniors (20/43 who listed stressors), $10 \%$ of juniors (2/20), 5\% of sophomores (1/18), and $0 \%$ of freshmen (0/9), cited the graduate application process as either a first, second, or third stressor. For the seniors, 19\% (8/43) listed it as a top stressor, 21\% (9/43) as a second stressor, and 7\% (3/43) as a third stressor. 
Table 2

Rankings of Stressors occuring 10\% of the time or more

\begin{tabular}{|c|c|}
\hline UGS & GS \\
\hline \multicolumn{2}{|l|}{ Stressor 1} \\
\hline School 74\% (66/74) & School 55\% (96/186) \\
\hline \multirow[t]{2}{*}{ Graduate school 10\% (9/89) } & Clinic 17\% (32/186) \\
\hline & Managing time $10 \%(18 / 180)$ \\
\hline \multicolumn{2}{|l|}{ Stressor 2} \\
\hline School 28\% (25/88) & School 52\% (92/178) \\
\hline Social issues $13 \%(11 / 88)$ & Family 38\% (67/178) \\
\hline \multirow[t]{3}{*}{ Finances $11 \%(10 / 88)$} & Clinic $20 \%(35 / 178)$ \\
\hline & Finances $11 \%(20 / 178)$ \\
\hline & Managing time $11 \%(20 / 178)$ \\
\hline \multicolumn{2}{|l|}{ Stressor 3} \\
\hline School 16\% (14/88) & School $22 \%(39 / 175)$ \\
\hline Work/GA 15\% (13/88) & Managing time $16 \%(28 / 175)$ \\
\hline Family $13 \%(11 / 88)$ & Social issues $10 \%(18 / 175)$ \\
\hline Social issues $13 \%(11 / 88)$ & Clinic 10\% (17/175) \\
\hline Finances 10\% (9/88) & \\
\hline
\end{tabular}

Note: Some respondents listed multiple stressors as top, second, or third rated stressor. Total listed stressors in each category were tallied and percent of occurrence is based on this total.

Stress Management Practices in Which UGS and GS Engage. To answer the sixth research question (i.e., What stress management practices do CSD UGS and GS engage in on their own?), an agreement index, as described in the section on stressors, was calculated for UGS' and GS' listings of their stress management practices. For UGS responses, the agreement index was $89 \%$ and for GS responses, it was 87\%. Both of these are acceptable levels of agreement. All disagreements were discussed until coders came to consensus.

Ten different themes of stress management practices arose from the data; six of these emerged as salient themes. For UGS, the top occurring stress management practice was maintaining a healthy lifestyle (diet, sleep, exercise, self-care plan), followed by taking time for self (take a break, take each day as it comes, look at the big picture), engaging in leisure time activities (listen to music, watch tv, shop, read, shower, bathe, drive, play video games), and managing time wisely (use a planner, stay on schedule, clean). For GS, the top listed practice was maintaining a healthy lifestyle, followed by taking time for self, engaging in a mindfulness practice (candles, aromatherapy, yoga, breathing, Reiki, journaling, meditation, positive self-talk), managing time wisely, and connecting with others (talk with family and friends, spend time with family, friends, pets). See Table 3. 
Table 3

Ranking of stress management practices by level

UGS $43 \%$ reported practice

$(38 / 89)$
GS $48 \%$ reported practice

$(83 / 174)$
Healthy lifestyle 33\% (20/60)

Time for self $20 \%(12 / 60)$

Leisure time $12 \%(7 / 60)$

$(6 / 60)$
Manage time $12 \%(17 / 144)$

Healthy lifestyle $28 \%(41 / 144)$

Time for self $17 \%(24 / 144)$

Mindfulness practice $16 \%(27 / 144)$ Manage time $10 \%$

Connect with others $10 \%(14 / 144)$

Note: Many participants reported more than one practice. Total number of separate reported practices were tallied and percent of occurrence is based on this total.

Influence of Stress Management Practices on Negative Aspects of Perfectionism and Perceived Stress. No differences existed between the scores of UGS and GS on the PSS or the Discrepancy subscale. Therefore, PSS and Discrepancy scores of UGS and GS were combined in the analysis done to answer the seventh research question (i.e., Is there an influence of engaging in stress management practices on reducing perceived stress levels and negative aspects of perfectionism?). Specifically, two independent t-tests were calculated. One with PSS scores as the criterion variable and stress management practice (yes vs. no) as the classification variable and the other with the Discrepancy subscale scores as the criterion variable and stress management practice (yes vs. no) as the classification variable. Because multiple t-tests were calculated, the Bonferroni correction was used to set the alpha level at .025.

The independent t-test result for PSS scores indicated a statistically significant difference existed between those who did participate in a stress management practice and those who did not $[\mathrm{t}(253)=-$ 2.91, $\mathrm{p}=.004]$. To determine effect size, Cohen's d was calculated. This equaled 0.37, which, according to Barry et al. (2016) is close to a medium effect size. Mean score for respondents with a practice was $19.79(\mathrm{SD}=6.72)$ and for those without a practice was $22.23(\mathrm{SD}=6.62)$. The independent t-test result for Discrepancy scores indicated no difference existed between those who did participate in a stress management practice and those who did not [t(233)=-1.82, $\mathrm{p}=.071]$. Mean score for those with a practice was $45.53(\mathrm{SD}=18.10)$ and for those without a practice was $49.72(\mathrm{SD}=17.17)$.

\section{Discussion}

The purpose of the current study was to provide increased information about perfectionism and perceived stress levels of CSD UGS and GS as well as items CSD students found to be stressful and what, if any, methods students used to manage their stress. Levels of perfectionism and 
perceived stress were found to be similar for UGS and GS. Both groups included fairly high numbers of perfectionistic students and perceived stress levels were overall somewhat elevated. A relationship existed between type of perfectionism and stress such that students who had maladaptive aspects of perfectionism were the most stressed whereas those with adaptive aspects of perfectionism were the least stressed. While many stressors listed by UGS and GS were similar, several differences also existed. Specifically, the graduate admission process was stressful for UGS and clinic was stressful for GS. A little less than half of each group of students reported participating in stress management practices. PSS scores of students who participated in stress management activities were lower than those of students who did not. APS-R Discrepancy subscores did not, however, differ between those who participated in stress management activities and those who did not.

Comparison of UGS and GS on Measures of Perfectionism and Stress. No differences were found between UGS and GS scores on the APS-R Discrepancy and Standards subscales. The lack of difference between these two groups on measures of perfectionism is not overly surprising given that perfectionism is a relatively stable aspect of a person's identity (Rice \& Dellwo, 2002). A person's perfectionistic tendency might not alter from the time the person is a UGS to the time the person is a GS, unless the person actively seeks to change this tendency. This reinforces the suggestion made by Rice et al. (2006) that support should be provided to college students who demonstrate characteristics of maladaptive perfectionism as early as possible.

A less expected finding was that there was no difference between UGS and GS on the PSS. Stress is caused by a person's reaction to a stressor. Lieberman et al. (2018) suggested that the stressors experienced by GS (e.g., greater financial concerns, decreased academic guidance and support, continuous evaluations, and high expectations for clinical performance) are of greater intensity than those experienced by UGS. The results of the current study indicated that the stressors experienced by UGS were of similar perceived intensity as were the stressors experienced by GS. CSD educators (i.e., faculty and clinical educators) should be as aware of the stressors being placed on UGS as they are of those being placed on GS.

Because no differences existed between UGS and GS on measures of perfectionism and perceived stress, the scores of UGS and GS were combined for other quantitative analyses. In the following sections type of perfectionism, level of stress, and the relationship between perfectionism and perceived stress are discussed for respondents as a whole.

Types of Perfectionism. On the basis of APS-R Standards and Discrepancy subscale scores, 74\% of the respondents were classified as perfectionistic, $33 \%$ as adaptive perfectionists, and $41 \%$ as maladaptive perfectionists. Rice and Dellwo (2002) also classified college students on the basis of APS-R scores and found that $50 \%$ of their sample was perfectionistic. These authors concluded that "dimensions of perfectionism are relatively pervasive personality constructs" (p. 194). Comparison of the results of the current study to those of Rice and Dellwo (2002), suggested perfectionism might be more pervasive in CSD students than it is in the general college population. 
Levels of Perceived Stress. CSD students who responded to the current survey appeared, on average, to have somewhat elevated levels of perceived stress. The mean PSS for all respondents was 21.06 ( $\mathrm{SD}=6.84$ ). This mean score was higher than the scores found by Cohen and JanickiDeverts (2012) in a large, national sample of individuals: mean scores for women and for individuals under 25 years of age were $16.14(\mathrm{SD}=7.56)$ and $16.78(\mathrm{SD}=6.86)$, respectively.

Stress Level by Type of Perfectionism. Results of the one-way ANOVA with type of perfectionism as the classification variable and PSS as the criterion variable indicated students with adaptive aspects of perfectionism had the lowest PSS scores followed by students who were nonperfectionistic. Students with maladaptive perfectionism had the highest PSS scores. The mean PSS score of adaptive perfectionists (i.e., 16.50, $\mathrm{SD}=5.27$ ) was very similar to the mean scores reported by Cohen and Janicki-Deverts (2012; see Stress section above) indicating typical PSS scores. A comparison of nonperfectionistic respondents' mean PSS score (i.e., 19.90, $\mathrm{SD}=6.41$ ) to the averages found by Cohen and Janicki-Deverts (2012) indicated their mean score was within one standard deviation above the norms suggesting slightly elevated perceived stress levels. Comparison of mean PSS scores of the respondents who were classified as maladaptive perfectionists (24.55, SD=5.84) to the norms found by Cohen and Janicki-Deverts (2012) indicated the mean PSS score of these respondents was greater than one standard deviation above the norms for women and for individuals under 25. Stress might exacerbate the negative emotional effects of maladaptive perfectionism (Rice et al., 2006). Therefore a vicious cycle might exist in which students who are the most stressed (i.e., those classified as maladaptive perfectionists) are also those who are most susceptible to further stress.

Relationship Between Negative Aspects of Perfectionism and Perceived Stress. Furthermore, a strong, positive correlation between PSS and Discrepancy scores was found. Respondents were categorized as adaptive perfectionists, maladaptive perfectionists, or nonperfectionists by comparing each respondent's APS-R Discrepancy and Standard subscale scores. According to Rice and Ashby (2007), maladaptive perfectionists have both elevated Discrepancy and Standard subscale scores; adaptive perfectionists have elevated Standard subscale scores, but lower Discrepancy subscale scores; and nonperfectionists have lower Standard subscale scores.

Discrepancy subscale scores are not considered when classifying nonperfectionists so they could be elevated or low. A review of the current data indicated that 38 of the 62 respondents classified as nonperfectionists had elevated Discrepancy scores (i.e., at or above 42). Thus, in addition to the respondents who were classified as maladaptive perfectionists, approximately $61 \%$ of nonperfectionistic respondents had elevated Discrepancy scores which were positively correlated with high PSS scores.

Additionally, nonperfectionists have lower APS-R Standard subscale scores. High Standards subscale scores have been associated with positive psychological outcomes (Rice et al., 2006). Rice and collaeagues suggested that stress might more negatively impact students with lower standards than it does students with higher standards. Therefore, students who are nonperfectionistic (i.e., have low Standards scores) and who have high Discrepancy scores, might be just as, or more, susceptible to the effects of stress than are students who are classified as maladaptive perfectionists. The results of the current study suggested that close to two thirds of 
the respondents, those classified as maladaptive perfectionists and nonperfectionists, might be more susceptible to the negative effects of stress than students who were classified as healthy, adaptive perfectionists.

Causes of Stress. To determine the greatest causes of stress for CSD students, respondents were asked to list their top three stressors in descending order. Similarities and differences appeared across the responses of UGS and GS respondents. One similarity was that for both groups of respondents, school-related items were the most frequently cited first, second, and third-level stressor. Other stressors that were cited by both UGS and GS respondents as either second or third level stressors were finances, family, and social issues. These stressors were commonly cited stressors for many other college students (Hurst et al., 2013; Lieberman et al., 2018). Indeed, Staats, Cosmar, and Kaffenberger (2007) compared sources of stress for college students in 1982 and in 2004. Their results suggested that, over the 20 years covered by their study, there was "a fairly stable and consistent pattern in what students worry about" (p. 694). The top stressors that were consistent across the 20 years were: "fear of falling behind on course work, financial worries, and worries about academic abilities" (p. 694). Problems in personal life was also listed as a top stressor across both cohorts (average rank of 5 in 1982 and of 6 in 2004; Staats et al., 2007).

Differences in stressors for UGS and GS respondents were also found. Only UGS, primarily seniors, listed the graduate school application process as a top stressor. Given that GS have already been accepted into graduate school, this was not a surprising difference. This item, however, might differentiate CSD UGS from UGS in other majors; graduate school application was not one of the stressors listed by Staats et al. (2007).

Another difference in stressors between UGS and GS found in the current study was clinic. GS listed clinic as the next greatest stressor after school-related items for their first stressor and also listed it as a second and third-level stressor. In 1985, Sleight studied speech-language pathology GS clinicians' anxiety levels. Her findings indicated that student clinicians showed anxiety before they began their initial practicum and that only some of this anxiety was reduced after completing their first practicum. Sleight (1985) stated that:

It is important for supervisors to recognize how their students feel about clinical practicum. Only if supervisors can identify areas of confidence or anxiety in their supervisees can they help students to grow and change as clinicians (p. 42).

Results of the current survey indicated clinical experiences still cause students anxiety and that it remains important for clinical educators to recognize how their students are feeling and what specific areas are causing them to be stressed or, conversely, to feel confident.

GS also reported managing time as a top, second, and third-rated stressor; UGS did not. Unlike most UGS, GS must manage the demands of clinic at the same time they are managing the demands of a full and challenging academic schedule. The CSD scope of practice has expanded over the past 30 years and GS students today enroll in courses and clinical experiences that provide them with knowledge and skills that cover the depth and breadth of all areas of practice. CSD educators 
must document that students have demonstrated successful acquisition of knowledge and skills not only in individual classes and clinical experiences, but across their entire program. To meet these demands and be successful in their graduate program, GS must manage their time continuously and wisely. Such careful management of time appeared to be one of the main factors adding to their perceived stress levels.

A difference was not found in perceived stress levels of UGS and GS and many of the stressors that were listed by respondents were similar to those found for college students in general (Hurst et al., 2013). Differences in what causes stress, however, also existed for UGS and GS respondents. CSD educators should be aware of students' primary stressors so they can provide appropriate supports to help students manage specific stressors.

Methods of Managing Stress. Just under half of both the UGS and GS respondents reported engaging in stress management practices. The top practice reported by both groups was trying to lead a healthy lifestyle (e.g., exercising, eating right, sleeping enough). Both groups also reported finding time for themselves and managing their time. Differences found between groups were that UGS engaged in leisure time activities while GS engaged in mindfulness practices and connecting with others.

Results of independent t-tests indicated that respondents to the current survey who engaged in a stress management practice had lower PSS scores than did those who did not. No influence of stress management practices, however, was found for APS-R Discrepancy subscale scores. The PSS is a measure of current perceived stress. Perfectionism, as opposed to perceived stress levels, might be a relatively stable aspect of a person's identity (Rice \& Dellwo, 2002). Thus engaging in a stress management practice might have reduced respondents' current perceived stress levels but not the more stable trait of maladaptive perfectionism.

Furthermore, the intention behind engaging in stress management and the specific type of stress management practice could influence the effectiveness of the strategy. Bland et al. (2012) conducted an epidemiological, cross-sectional study to identify various coping strategies used by millennial college students to manage stress and to determine which strategies were effective. Strategies that decreased students' tolerance for stress were cleaning, calling a friend, using social media, praying, taking study breaks, calling Mom, shopping, eating, and using substances. Many of these strategies were coded in the current study as time for self, leisure time activities, and connecting with others. Bland et al. (2012) suggested that strategies such as these might place reliance for stress management on external factors and fall into the category of avoidant coping skills.

The only strategy assessed by Bland et al. (2012) that was found to be a significant factor in protecting students from stress was feeling "supported by family, friends, and teachers" (p. 372). Similarly, one of the most frequent responses given by CSD participants in Lieberman et al. (2018) when asked what they believed would help reduce stress, was "frequent communication with faculty" (p. 7). In the current study, this factor would have been coded as connecting with others. 
Bland et al. (2012) suggested that feeling truly supported and loved is a powerful, approachoriented coping skill.

Managing time wisely and engaging in mindfulness practices were two other stress management themes cited by respondents to the current study that were not included in strategies assessed by Bland et al. (2012). Time management skills are important and could help individuals feel more organized and less overwhelmed. Aeon and Aguinis (2017) indicated that time management skills have been found to improve overall wellness and reduce stress. Engaging in mindfulness practices has also been documented to reduce CSD students' stress (Beck, Seeman et al., 2015; Beck \& Verticchio, 2014; Beck et al., 2017). Both of these stress management techniques could be thought of as approach-oriented coping strategies that facilitate a person's ability to manage stressful situations appropriately and are strategies instructors could assist students in developing.

The type of stress management practice, and the intention behind using it are important determinants in the efficacy of the practice (Bland et al., 2012). Some practices, especially those that allow students' to avoid dealing with the stressors, can cause students to be more susceptible to the effects of stress. These are also the types of strategies that students who have higher stress levels (i.e., maladaptive perfectionists and nonperfectionists) use frequently (Noble et al., 2014). Stress management practices that facilitate students' ability to actively approach and deal with stressors can increase stress resilience. Noble et al. (2014) indicated that students who are adaptive perfectionists (i.e., students with lower levels of stress) often use active, task-oriented strategies. All students should be encouraged to engage in those practices that have been documented to increase stress resilience.

\section{Limitations and Directions for Further Research}

While respondents came from 15 different institutions, all of them were within the Midwestern area of the United States. This survey should be replicated with students from across the entire country to determine if similarities and differences exist in perfectionism and perceived stress for students from various geographical areas of the country.

Additionally, only the results of students in CSD programs were reported in the current study. Comparison of levels of perceived stress and levels and types of perfectionism between students in CSD and in those majoring in other disciplines would provide additional information regarding our students and factors that might or might not be specific to them.

\section{Conclusion}

A notable number of CSD students appear to have maladaptive aspects of perfectionism and high levels of perceived stress. Other students might be nonperfectionistic and predisposed to the negative effects of stress. As individuals who work with these students, it is important that CSD educators recognize the student characteristics and the environmental factors that cause and potentially exacerbate negative physical and psychological consequences for them. When 
educators are aware of these factors, they can actively endeavor to enhance students' overall wellbeing.

Christman (2012) indicated that many perfectionistic students will not seek out help because they view this as "an admission of failure" (p. 204). This places greater responsibility on educators to be aware of students' behaviors that might require intervention. Christman (2012) discussed the importance of referring students to qualified mental health experts if necessary. She also suggested several actions in which educators can engage. Educators can "stress the importance of learning from one's mistakes" (Christman, 2012, p. 204) and can serve as role models who demonstrate that all individuals make mistakes and can still continue to learn and grow.

The results of the current study indicated that engaging in stress management practices might also help students reduce perceived stress levels. If respondents had engaged in primarily approachoriented strategies, an influence of the practice on negative perfectionism might also have been found. Suggestions from other literature (e.g., Aeon \& Aguinis, 2017; Beck et al., 2017; Bland et al., 2012), in conjunction with the results of the current study, indicate that CSD educators can help students develop positive coping strategies by educating them about potentially negative, avoidance-oriented strategies and by helping them develop more appropriate strategies such as good time-management skills and practices that enhance mindfulness. Above all, CSD educators can convey that they are available to support students and to encourage their positive growth as professionals and people.

\section{Financial disclosure statements}

Ann Beck is employed by Illinois State University, at which the survey was conducted. This is a continuing relationship until June 30, 2019 at which time Ann Beck will retire.

Heidi Verticchio is employed by Illinois State University, at which the survey was conducted. This is a continuing relationship and Heidi Verticchio has been by ISU 20 years

Ali Miller was a graduate assistant at Illinois State University during the time the survey was conducted. Ali Miller graduated and is no longer an employee of Illinois State University.

\section{Nonfinancial disclosure statements}

Ann Beck has no nonfinancial disclosures.

Heidi Verticchio has no nonfinancial disclosures.

Ali Miller has no nonfinancial disclosures. 


\section{References}

Aeon B., \& Aguinis, H. (2017). It's about time: New perspectives and insights on time management. Academy of Management Perspectives, 31, 309-330. https://doi.org/10.5465/amp.2016.0166

Alden, L. E., Ryder, A. G., \& Mellings, T. M. B. (2002). Perfectionism in the context of social fears: Toward a two-component model. In G. L. Flett \& P. L. Hewitt (Eds.), Perfectionism: Theory, Research, and Treatment (pp. 373-391). Washington, D.C.: American Psychological Association.

Ashby, J. S., \& Gnilka, P. B. (2017). Multidimensional perfectionism and perceived stress: Group differences and test of a coping mediation model. Personality and Individual Differences, 119, 106-111. doi: 10.1016/j.paid.2017.07.012

Barry, A. E., Szucs, L. E., Reyes, J. V., Ji, Q., Wilson, K. L., \& Thompson, B. (2016). Failure to report effect sizes: The handling of quantitative results in published health education and behavior research. Health Education \& Behavior, 43(5), 518-527. doi: $10.1177 / 1090198116669521$

Beck, A., Seeman, S., Verticchio, H., \& Rice, J. (2015). Yoga as a technique to reduce stress experienced by CSD graduate students. Contemporary Issues in Communication Sciences and Disorders, 42,1-15.

Beck, A., \& Verticchio, H. (2014). Facilitating speech-language pathology graduate students' ability to manage stress: A pilot study. Contemporary Issues in Communication Sciences and Disorders, 41, 24-38.

Beck, A., Verticchio, H., \& Schaab, H. (2015, November). Perfectionism, Stress, \& CSD Students. Poster session presented at the American Speech-Language-Hearing Association Convention, Denver, CO.

Beck, A., Verticchio, H., Seeman, S., Milliken, E., \& Schaab, H. (2017). A mindfulness practice for CSD undergraduate and SLP graduate students: Effects on stress, self-compassion and perfectionism. American Journal Speech-Language Pathology, 26, 893-907. doi: 10.1044/2017_AJSLP-16-0172

Bland, H. W., Melton, B. F., Welle, P., \& Bigham, L. (2012). Stress tolerance: New challenges for millennial college students. College Student Journal, 46, 236-375.

Christman, E. (2012). Understanding maladaptive perfectionism in college students. Nurse Educator, 37 (5), 202-205.

Cohen, S. (1994). Perceived Stress Scale [PDF]. Retrieved from https://www.mindgarden.com/documents/PerceivedStressScale.pdf

Cohen, S., \& Janicki-Deverts, D. (2012). Who's stressed? Distributions of psychological stress in the United States in probability samples from 1983, 2006, and 2009. Journal of Applied Social Psychology, 42, 1320-1334. doi: 10.1111/j.1559-1816.2012.00900.x

Enns, M. W., \& Cox, B. J., (2002). The nature and assessment of perfectionism: A critical analysis. In G. L. Flett, \& P. L. Hewitt (Eds.), Perfectionism: Theory, Research, and Treatment (pp. 33-62). Washington, D.C.: American Psychological Association.

George, D., \& Mallery, P. (2006). SPSS for windows step by step: A simple guide and reference $\left(6^{\text {th }}\right.$ edition $)$. Boston, MA: Pearson.

Hatch, J.A. (2002). Doing qualitative research in education settings. Albany, NY: State University of NY. 
Hewitt, P. L., \& Flett, G. L. (2002). Perfectionism and stress processes in psychopathology. In G. L. Flett, \& P. L. Hewitt (Eds.), Perfectionism: Theory, Research, and Treatment (pp. 255284). Washington, D.C.: American Psychological Association.

Hill, A. P., \& Curran, T. (2016). Multidimensional perfectionism and burnout: A meta-analysis. Personality and Social Psychology Review, 20, 269-288. doi:

10.1177/1088868315596286

Hurst, C. S., Baranik, L. E., \& Daniel, F. (2013). College student stressors: A review of the qualitative research. Stress and Health, 28, 275-285. doi: 10.1002/smi.2465

Lieberman, R., Raisor-Becker, L., Sotto, C., \& Redle, E. (2018). Investigation of graduate student stress in speech language pathology. Teaching and Learning in Communication Sciences and Disorders, 2(2). doi: doi.org/10.30707/TLCSD2.2Lieberman

Lincoln, M., Adamson, B., \& Covic, T. (2004). Perceptions of stress, time management and coping strategies of speech pathology students on clinical placement. Advances in Speech-Language Pathology, 6 (2), 91-99.

McCall, T. (2007). Yoga as medicine: The yogic prescription for health and healing. New York, NY: Bantam.

Noble, C. L., Ashby, J. S., \& Gnilka, P. B. (2014). Multidimensional perfectionism, coping, and depression: Differential prediction of depression symptoms by perfectionism type. Journal of College Counseling, 17, 80-94. doi: 10.1002/j.2161-1882.2014.00049.x

Orlikoff, R. F., Schiavetti, N., \& Metz, D. E. (2015). Evaluating research in communication Disorders $\left(7^{\text {th }}\right.$ ed.). Boston, MA: Pearson.

Prud'homme J., Dunkley, D. M., Bernier, E., Berg, J., Ghelerter, A., \& Starrs, C.J. (2017). Specific perfectionism components predicting daily stress, coping, and negative affect six months and three years later. Personality and Individual Differences, 111, 134-138.

Rice, K. G., \& Ashby, J. S. (2007). An efficient method for classifying perfectionists. Journal of Counseling Psychology, 54, 72-85. doi: 10.1037/0022-0167.54.1.72

Rice, K. G., \& Dellwo, J. P. (2002). Perfectionism and self-development: Implications for college adjustment. Journal of Counseling and Development, 60, 188-196.

Rice, K. G., Leever, B. A., Christopher, J., \& Porter, J. D. (2006). Perfectionism, stress, and social (dis)connection: A short-term study of hopelessness, depression, and academic adjustment among honors students. Journal of Counseling Psychology, 53, 524-534. doi: 10.1037/0022-0167.53.4.524

Rizzolo, D., Zipp, G. P., Stiskal, D., \& Simpkins, S. (2009). Stress management strategies for students: The immediate effects of yoga, humor, and reading on stress. Journal of College Teaching \& Learning, 6 (8), 79-88.

Ross, E. (2011). Burnout and self-care in the practice of speech pathology and audiology: An ecological perspective. In R. J. Fourie (Ed.), Therapeutic processes for communication disorders (pp. 213 - 228). New York, NY: Psychology Press.

Sapolsky, R. M., (2004). Why zebras don't get ulcers ( $3^{\text {rd }}$ ed.). New York, NY: Holt Paperbacks.

Slaney, R.B. (2015) APS-Revised [PDF]. Retrieved from: http://kennethwang.com/apsr/scales/APS-R_96.pdf

Slaney, R. B., Rice, K. G., \& Ashby, J. S., (2002). A programmatic approach to measuring perfectionism: The Almost Perfect Scales. In G. L. Flett, \& P. L. Hewitt (Eds.), Perfectionism: Theory, Research, and Treatment (pp. 63-88). Washington, D.C.: American Psychological Association. 
Slaney, R. B., Rice, K. G., Mobley, M., Trippi, J., \& Ashby, J.S. (2001). The Revised Almost Perfect Scale. Measurement and Evaluation in Counseling and Development, 34, 130145.

Sleight, C. (1985). Confidence and anxiety in student clinicians. The Clinical Supervisor, 3 (3), 25-48.

Staats, S., Cosmar, D., \& Kaffenberger, J. (2007). Sources of happiness and stress for college students: A replication and comparison over 20 years. Psychological Reports, 101, 685696. doi: 10.2466/PR0.101.3.685-696

Stoeber, J., \& Otto, K. (2006). Postive conceptions of perfectionism: Approaches, evidence, challenges. Personality and Social Psychology Review, 10, 295-319. doi: 10.1207/s15327957pspr1004_2

Suh, H., Gnilka, P.B., \& Rice, K. G. (2017). Perfectionism and well-being: A positive psychology framework. Personality and Individual Differences, 111, 25-30. 